\title{
Gastric GIST: A Rare Cause of Upper GI Bleeding
}

\author{
Rahman MM', Ahmed T ${ }^{2}$, Hassan MR $^{3}$, Islam $\mathbf{M}^{4}$
}

Conflict of Interest: None

Received: 22.03 .2020

Accepted: 28.07 .2020

www.banglajol.info/index.php/JSSMC

\section{Key Words:}

Gastrointestinal stromal tumour

(GIST), Melena, Lower partial

gastrectomy, Immunohistochemistry

\begin{abstract}
Gastrointestinal stromal tumours are the most common mesenchymal tumours of the gastrointestinal tract. This case report highlights the necessity of early surgical intervention in such cases to avoid mortality due to bleeding and to raise the awareness of rare causes of upper gastrointestinal bleed and their management. A 19 year old male presented in the surgery department of Shaheed Suhrawardy medical College Hospital with complaints of recurrent episodes of melena with anorexia and weight loss for 6 months. Apart from anaemia no significant findings were noted on physical examination. Investigations including upper GI endoscopy was not conclusive. So he underwent laparotomy which revealed an exophytic growth along the lesser curvature. Lower partial gastrectomy was done and histopathological and immunohistochemistry report showed evidence of benign low risk GIST. As the tumor was benign with no malignant potential imatinib therapy was not advocated.
\end{abstract}

[J Shaheed Suhrawardy Med Coll 2020; 12(2): 119-122] DOI: https://doi.org/10.3329/jssmc.v12i2.56894

\section{Introduction}

Gastrointestinal stromal tumors (GISTs) comprise a rare group of neoplasms with unpredictable malignant potential and an annual incidence of 4 / 1000000 persons . ${ }^{1}$ Though relatively rare, GIST is the most common mesenchymal tumors of the gastrointestinal tract. The common sites of location are in order the stomach, the small intestine, the rectum, the esophagus and a small percent may be located elsewhere in the abdominal cavity. ${ }^{2}$ Gastric stromal tumor is a submucosal tumor which is different from leiomyoma, leiomyosarcoma and neurogenic tumors. On the basis of their appearance on light microscopy, GISTs were first thought to be of originated from smooth muscle. Most were classified as leiomyosarcomas or epitheloid leiomyosarcomas. The diagnosis of GIST is secured by immunohistochemical staining for the tyrosine kinase receptor which is known as CD 117, which highlights the presence of interstitial cells of Cajal. ${ }^{2}$ CD 117 expression also differentiates GISTs from true leiomyomas and gastric

1. Prof. Md Mustafizur Rahman, Professor \& Head, Department of Surgery, Shaheed Suhrawardy Medical College Hospital, Dhaka

2. Dr. Tanvir Ahmed, Registrar (Surgery), Department of Surgery, Shaheed Suhrawardy Medical College Hospital, Dhaka

3. Dr. Mohammad Rashedul Hassan, Indoor Medical Officer (Surgery), Department of Surgery, Shaheed Suhrawardy Medical College Hospital, Dhaka

4. Dr. Mansurul Islam, Assistant Regfistrar (Surgery), Department of Surgery, Shaheed Suhrawardy Medical College Hospital, Dhaka

Address of Correspondence: Prof. Md Mustafizur Rahman, Professor \& Head, Department of Surgery, Shaheed Suhrawardy Medical College Hospital, Dhaka. Mobile No. : 01711619767. Email:drmustafiz@hotmail.com schwannomas which are consistently negative for CD 117. Approximately two thirds of GISTs also express CD $34 .{ }^{3} \mathrm{CD} 117$ is regarded as a key confirmatory marker in the diagnosis of this tumor. ${ }^{3}$ Histologically, these tumors may exhibit a spindle cell pattern, an epithelioid pattern, or a mixed subtype. ${ }^{3}$ Diagnosis of this condition is sometimes difficult and treatment is often delayed because patients usually present with nonspecific abdominal symptoms. GISTs are associated with nonspecific symptoms. No physical findings specifically suggest the presence of a GIST. The main manifestation of GISTs is acute or chronic upper gastrointestinal hemorrhage (61\%). ${ }^{4}$ Gastroscopy, endoscopic ultrasound, abdominal and pelvic imaging are helpful to diagnosis. The final diagnosis is decided by pathological and immunohistochemical examination. ${ }^{5}$

Although most gastric GISTs have a benign course, a wide spectrum of biologic behavior has been observed. ${ }^{6}$ A combination of prognostic factors (patient age, tumor size, histologic type, degree of necrosis, cellularity, nuclear pleomorphism, mitotic activity, and DNA analysis have been used to predict their behavior. ${ }^{7}$ There is reluctance to use the term "benign" to describe GISTs since this tumor may be unpredictably malignant. Patients with GISTs may be categorized into very low, low, intermediate, and high risk on the basis of an estimation of their potential for recurrence and metastasis. ${ }^{8}$ The operative treatment is the first choice and complete surgical resection is the most definitive treatment. ${ }^{9}$ Here we present a case of 19 year old boy of gastric GIST presented with upper GI haemorrhage. 


\section{Case summary}

A 19 year old male was admitted to the surgery department of Shaheed Suhrawardy Medical College Hospital with the complaints of passage of black tarry stool for 6 months. He also gave history of anorexia, generalized weakness with weight loss for same duration. The patient received 6 units of blood during his course of illness. On examination he was anaemic, non-icteric and his vitals were within normal limit. Per abdominal examination revealed no abnormality. Findings of other systemic examinations were unremarkable. His blood picture showed normocytic normochromic anaemia. His other blood reports including coagulation profile, liver and renal function tests were normal. Ultrasonogram of whole abdomen also showed normal findings. Several upper GIT Endoscopy were done and one endoscopy revealed three submucosal swelling which suggested gastric polyp.(Fig-1) Histopathology report showed that it was a case of chronic gastritis. As all the test results were not conclusive and patient was still bleeding, the patient underwent diagnostic laparotomy.
There was an exophytic growth along the lesser curvature extended up to the antrum with no evidence of liver, peritoneal, omental or lymph nodal lesions.(Fig-2) Preoperative findings suggested that it could be a case of Gastric GIST. Patient underwent lower Partial Gastrectomy and the specimen was send for histopathology and report resulted that it was a case of gastric GIST (Gastrointestinal stromal tumor) which was confirmed by immuinohistochemistry. The histology report showed well circumscribed, non-encapsulated tumour within submucosa and muscularis propria. On microscopy the tumour was composed of spindle cells with no significant nuclear pleomorphism. The mitotic count was not high with no evidence of dysplasia or malignancy of overlying gastric mucosa. Immunostaining of the tumor cells were strongly positive for $\mathrm{CD} 117$ and negative for S100, desmin, smooth muscle, and actin. The above features strongly suggested the benign nature of GIST. His post-operative period was uneventful and he was discharged with advice on $10^{\text {th }}$ post-operative day.

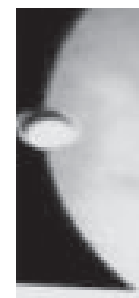

Procedure : UPPER G. I. TRACT ENDOSCOPY

Medication: Sedation by Dr. Kutub Uddin Khan MBBS FCPS, MCPS,

\section{Findings:}

Oesophagus

Sitgmach

- Altered biood seen at the stomach. Three giant the lesser curvature

Duodenum

- Normal upto 2nd part.

Biopsy

\section{COMMENTS :}

See Description Please.

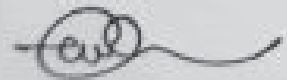

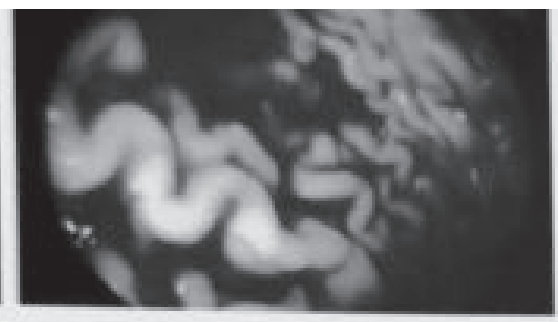
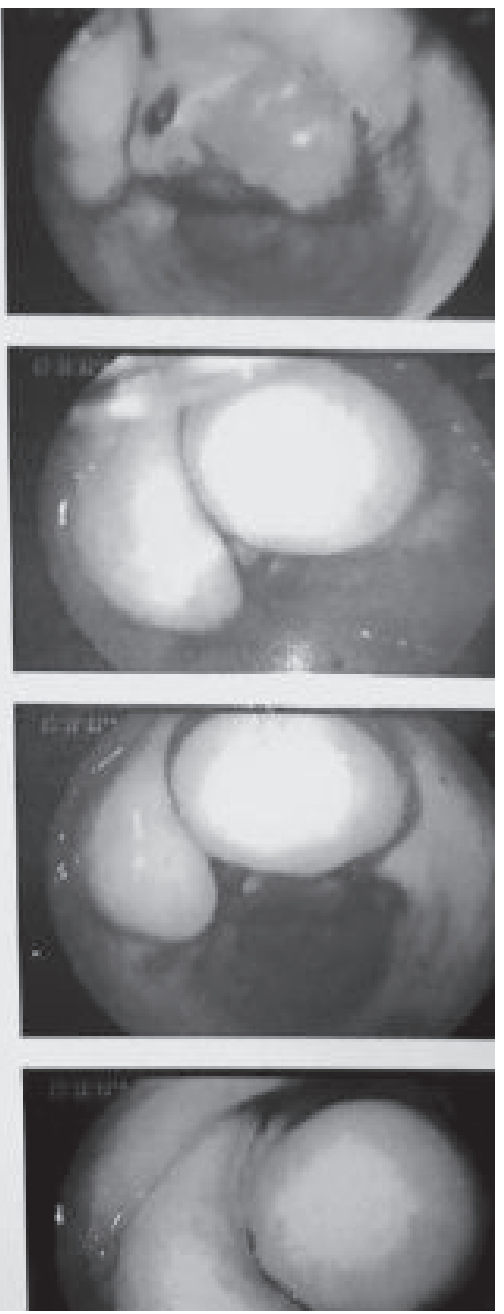

Fig.-1: Showing submucosal swelling along the lesser curvature 


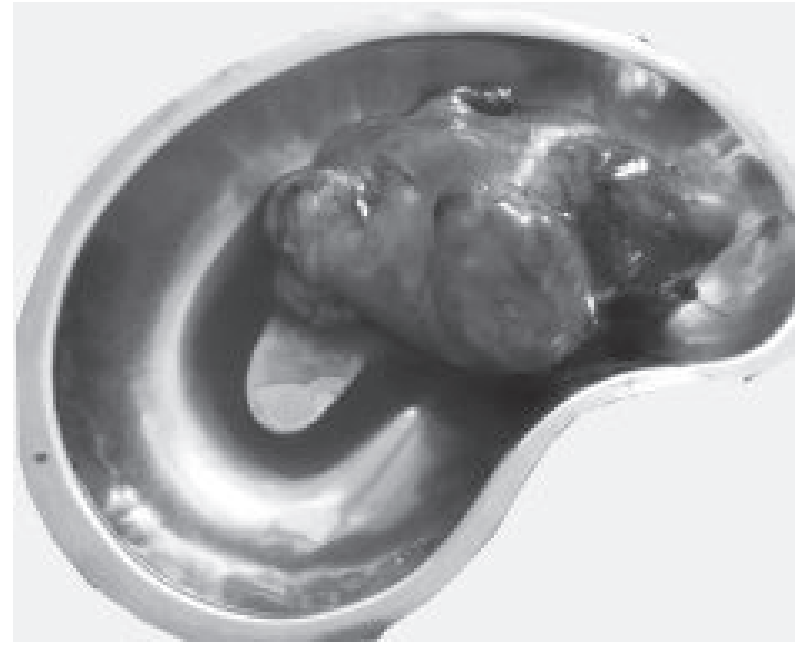

Fig.-2: showing specimen of stomach along with tumor

\section{Discussion}

Gastro-intestinal stromal tumours (GIST) are the most common mesenchymal tumours of the gastro-intestinal tract. They account for approximately 0.1 to $3 \%$ of all GI neoplasms. ${ }^{10}$ Usually, GISTs present in middle age people with a peak age of presentation at 58 years, affecting males and females equally. ${ }^{11}$ They rarely occur in children or young adults, but when they do, an association with neurofibromatosis and Carney's triad (gastric stromal tumor, extra adrenal paraganglioma and pulmonary chordoma) has been noted. ${ }^{12}$ Though our patient was young male of 19 years who presented with gastric GIST but no association with Carney's triad was found.

The clinical presentation of GISTs is variable. It depends on the size and organ involvement. Asymptomatic GISTs are found incidentally during surgery, endoscopy or CT scan for other conditions. Gastric GISTs usually present with vague abdominal pain, dyspepsia, and vomiting. They rarely present with secondary complications such as upper GI bleeding and perforation. ${ }^{13}$ Our patient also presented with upper GI bleeding. But as GISTs as a cause of upper GI bleeding is rare, there was a diagnostic dilemma and finally the diagnosis was made by per-operative findings.

GIST is an unusual cause of Upper GI bleeding, and has a high propensity to rebleed. These bleeding tumours need to be investigated urgently as an inpatient rather than as an outpatient. Early surgical intervention, either open or laparoscopic resection, is the treatment of choice to prevent rebleeding. In general, complete surgical resection is accomplished in 40-60\% of all GIST patients and in $>70 \%$ of those with primary non-metastatic GIST. ${ }^{14}$ In our case we were able to completely excise the tumour.

GISTs exhibit a highly variable behaviour after resection of the primary tumour. These patients need to be followed up on a long term basis as local recurrence and metastases can occur many years after surgery. These tumours spread by the haematogenous route predominantly to the liver. ${ }^{14}$ Lymph node involvement in very rare and therefore lymphadenectomy is not routinely indicated. In general, local recurrence or metastases develop in approximately $50 \%$ of patients who had potentially curative operation. ${ }^{15}$ The median disease specific survival for patients with primary GIST is approximately 5 years. ${ }^{15}$ The two most important tumor factors for local recurrence and metastasis are tumour size and mitotic rate (size $>5 \mathrm{cms}$ and mitosis $>5$ per $50 \mathrm{HPF}$ increases the risk). ${ }^{16}$ Other prognostic factors are completeness of resection, age, and tumor location. Histopathology report of our patient suggested that it was a low risk benign GIST.

Before the Imatnib era surgical resection was the only option available as GIST are highly resistant to chemotherapy and radiotherapy. The 5 year survival rate was $35-65 \%$ following complete resection and the medial survival rate was 10-20 months for unresectable disease. ${ }^{17}$ The introduction of Imatinib mesylate, a tyrosine kinase inhibitor, has dramatically improved the outcomes of treatment. ${ }^{17}$ It had demonstrated in clinical trials a significant decrease in tumour size rendering initially inoperable tumour resectable. Imatinib is currently recommended in high risk and intermediate risk group. ${ }^{18}$ Metastatic and inoperable GIST are other indication for imatinib therapy. ${ }^{18}$ As our patient was in low risk group so no further imatinib therapy was advised.

\section{Conclusion}

GIST is an unusual cause of upper GI bleeding. Early surgical intervention is the treatment of choice to prevent bleeding. All suspected mesenchymal tumors of GI should be tested for CD117 by an experienced histopathologist. Following surgery, all patients must be referred to higher centers which have more experience in treating GIST. Early diagnosis and complete surgical resection can provide a better prognosis of the patients.

\section{References}

1. Matthews BD, Joels CS, Kercher KW, Heniford BT. Gastrointestinal stromal tumors of the stomach. Minerva Chir 2004; 59: 219-231.

2. Thomas A, Sing A. Role of positron emission tomographic imaging in gastrointestinal stromal tumors. Appl Radiol 2005; 34: $10-17$.

3. Fletcher CD, Berman JJ, Corless C. Diagnosis of gastrointestinal stromal tumors: A consensus approach. Hum Pathol 2002; 33: 459-465.

4. Li J, Liu P, Wang H, Yu J, Xie P, Liu X. Clinical analysis of 31 patients with gastric stromal tumors. Zhonghua Nei Ke Za Zhi 2002; 41: 742-745. 
5. Brandimarte G, Tursi A, Elisei W, Annunziata V, Monardo E. Symptomatic gastric leiomyoma mimicking giant gastric polyp: endoscopic diagnosis and removal. Eur Rev Med Pharmacol Sci 2004; 8: 107-110.

6. Ludwig DJ, Traverso LW. Gut stromal tumors and their clinical behavior. Am J Surg 1997;173: 390-394.

7. De Silva CM, Reid R. Gastrointestinal stromal tumors (GIST): C-kit mutations CD117 expression differential diagnosis and targeted cancer therapy with Imatinib. Pathol Oncol Res 2003; 9: 13-19.

8. DeMatteo RP, Lewis JJ, Leung D, Mudan SS, Woodruff JM, Brennan MF. Two hundred gastrointestinal stromal tumors: recurrence patterns and prognostic factors for survival. Ann Surg 2000; 231: 51-58.

9. Xu GQ, Zhang BL, Li YM et al. Diagnostic value of endoscopic ultrasonography for gastrointestinal leiomyoma. World J Gastroenterol 2003; 9: 2088-2091.

10. Fujimoto Y, Nakanishi Y, Yoshimura K, Shimoda T. Clinicopathologic study of primary malignant gastrointestinal stromal tumor of the stomach, with special reference to prognostic factors; analysis of results in 140 surgically resected patients. Gastric Cancer 2003; 6: 39-48.

11. Sarlomo-Rikala M, Tsujimura T, Lendahl U, Miettinen M. Patterns of nestin and other intermediate filament expression distinguish between gastrointestinal stromal tumors, leiomyomas and schwannomas. APMIS 2002; 110: 499-507.
12. Fletcher CD, Berman JJ, Corless C et al. Diagnosis of gastrointestinal stromal tumors: a consensus approach. Int $\mathrm{J}$ Surg Pathol 2002; 10: 81-89.

13. Emory TS, Sobin LH, Lukes L, Lee DH, O’Leary TJ. Prognosis of gastrointestinal smooth-muscle (stromal) tumors: dependence on anatomic site. Am J Surg Pathol 1999; 23: 82- 87 .

14. Bilimoria MM, Holtz DJ, Mirza NQ et al. Tumor volume as a prognostic factor for sarcomatosis. Cancer 2002; 94: 24412446.

15. Bucher P, Egger JF, Gervaz P et al. An audit of surgical management of gastrointestinal stromal tumours (GIST). Eur J Surg Oncol 2006; 32: 310-314.

16. Blackstein ME, Blay JY. Gastrointestinal stromal tumours: consensus statement on diagnosis and treatment. Can J Gastroenterol 2006; 20 (3): 157-163.

17. Boggs W. Imatinib improves resectability of residual metastatic GIST disease. Int J Cancer 2005; 117: 316-325.

18. Antoch G, Kanja J, Bauer S et al. Comparison of PET, CT, and dual-modality PET/CT imaging for monitoring of imatinib (STI571) therapy in patients with gastrointestinal stromal tumors. J Nucl Med 2004; 45: 357-365. 